\title{
Role of transformational leadership on employee productivity of teaching hospitals: using structural equation modeling
}

Soudabeh Vatankhah ${ }^{1}$, Samira Alirezaei ${ }^{2}$, Omid Khosravizadeh $^{3}$, Seyyed Elmira Mirbahaeddin ${ }^{4}$, Mahtab Alikhani $^{5}$, Mobarakeh Alipanah ${ }^{6}$

${ }^{1}$ Associate Professor of Health Services Management Department, School of Health Management and Information Sciences, Iran University of Medical Sciences, Tehran, Iran

${ }^{2}$ Health Management and Economics Research Center, Iran University of Medical Sciences, Tehran, Iran

${ }^{3}$ Social Determinants of Health Research Center, Qazvin University of Medical Sciences, Qazvin, Iran

${ }^{4}$ Department of Healthcare Management, School of Public Health, Tehran University of Medical Sciences

${ }^{5}$ Student Research Committee, Zabol University of Medical sciences, Zabol, Iran

${ }^{6}$ Students' Scientific Research center, Exceptional Talents Development Center, Tehran University of Medical Sciences, Tehran Iran

Type of article: Original

\begin{abstract}
Background: In today's transforming world, increased productivity and efficient use of existing facilities are practically beyond a choice and become a necessity. In this line, attention to change and transformation is one of the affecting factors on the growth of productivity in organizations, especially in hospitals.

Aim: To examine the effect of transformational leadership on the productivity of employees in teaching hospitals affiliated to Iran University of Medical Sciences.

Methods: This cross-sectional study was conducted on 254 participants from educational and medical centers affiliated to Iran University of Medical Sciences (Tehran, Iran) in 2016. The standard questionnaires of Bass \& Avolio and of Hersi \& Goldsmith were used to respectively assess transformational leadership and level of productivity. The research assumptions were tested in a significance level of 0.05 by applying descriptive statistics and structural equations modeling (SEM) using SPSS 19 and Amos 24.

Results: Results of the fitting indicators of the assessing model after amending includes Chi-square two to degrees of freedom of 2.756, CFI indicator 0.95 , IFI indicator 0.92 , Root mean square error of approximation (RMSEA) indicator 0.10. These results indicate that the assessing model is well fitting after the amendment. Also, analysis of the model's assumptions and the final model of the research reveals the effect of transformational leadership on employees' productivity with a significance level of $0.83(\mathrm{p}=0.001)$.

Conclusion: This research indicates that the more the leadership and decision-making style in hospitals lean towards transformational mode, the more positive outcomes it brings among employees and the organization due to increased productivity. Therefore, it is essential to pay focused attention to training/educational programs in organizations to create and encourage transformational leadership behaviors which hopefully lead to more productive employees.
\end{abstract}

Keywords: Transformational leadership, Productivity, Teaching hospital

\section{Introduction}

Currently the situational effect of reciprocal interactions between organizations and the environment has led to their growth and survival and it is seen as constant change in social organizations. Managers in today's organizations face organizational development to stay compatible with environmental changes on the one hand and on the other hand, they are faced with the challenge of how to direct energies, especially human resources, in a way that the

\section{Corresponding author:}

Samira Alirezaei, Health Management and Economics Research Center, Iran University of Medical Sciences, Tehran, Iran. Tel: +98.2188778069, Fax:+98.2188794301, Email: s.alirezaei.6856@gmail.com

Received: October 04, 2016, Accepted: May 22, 2017, Published: August 2017

iThenticate screening: April 21, 2017, English editing: June 16, 2017, Quality control: July 26, 2017

(C) 2017 The Authors. This is an open access article under the terms of the Creative Commons Attribution-NonCommercialNoDerivs License, which permits use and distribution in any medium, provided the original work is properly cited, the use is non-commercial and no modifications or adaptations are made. 
organization's goals are realized and the system mission is performed while the employees' needs are also provided. Among the organizational resources, human resources are considered as one of the most major and critical factors of any organization, having a significant role in the quality and quantity of the organization's outcomes. This reason has caused more attention to productivity and transformation of human resources and determination of its position and share in production of services (1). For every effective change in an organization, it is essential that beliefs, assumptions and attitudes of individuals are challenged and clarified since study of psychological characteristics and mutual interactions, incentives and human attitudes as the most significant element of the organization can be of prominent importance. Meanwhile, leadership is a determining role as the points of view and people's attitudes for performing transformation and change depend on the style and mode of existing type of leadership in the organization (2). In recent years great attention has been paid to testing the new managerial model of transformational leadership (TL) (3). In fact, TL is defined as a process of conscious influence on individuals or groups with the aim of creating discontinuous change and transformation in current state and functions of an organization as a whole. TL transforms the whole organization through its conversation and behavior, and has a great influence on its followers (4). On the other hand, one of the organization's concerns in micro and macro level in production and service level is productivity and identification of affecting factors (5). One of the pivotal service organizations are hospitals and healthcare centers in which productivity, and consequently, improvement of healthcare services quality has become an important priority in managers' decision making and activities in order to stay responsive of the public's healthcare needs and expectations (6). However, in the current state, increased productivity and efficient use of existing facilities is practically beyond a choice, and has become a necessity. Therefore, managers are required to apply an appropriate system to measure productivity. This system needs to show the whole performance of the hospital and identify the affecting factors on its productivity so that the inefficient items causing decrease in efficiency and effectiveness, and eventually productivity, are understood (7). The findings are in accordance with a study conducted by Davis in New Zealand (8), also findings of a study from 22 hospitals in Greece (9), another study in Netherlands in different periods (10) and a study in South Korea about productivity of Nurses (11). Moreover, regarding TL in hospitals, it can be referred to studies such as a study by Weng regarding the effect of TL on nurses' creativity and another one by Hayati on transformation and work interactions in public hospitals (12), and also a research by Top regarding TL and job satisfaction in Turkey's hospitals (13). Although numerous studies have been conducted in Iran and other countries, regarding affecting factors on productivity in hospitals, the impact of a prominent element such as TL on hospital productivity has been rarely examined, and since one of influencing factors on productivity growth in organizations, especially hospitals, is attention to change and transformation, this study aims to investigate the effect of TL on the productivity of employees in teaching hospitals of Iran. Its results can lead to identification of affecting components of TL on hospital productivity and provision of strategies to utilize human resources appropriately, and eventually improve their productivity.

\section{Material and Methods}

The present study is a cross-sectional and descriptive-analytic study in terms of objective and time, and it has an applied/practical nature with 245 participants. Study population included all para-clinics, supporting and financial departments' employees of selected educational and medical centers affiliated to Iran University of Medical Sciences. First, random sampling of educational and medical centers' population of the university was done, and out of ten centers four centers were filtered by simple random selection, including Shahid Hashemi Nejad Center, Shahid Motahari, Hazrate Zahra and Firouzgar. To select a sample out of total employees in the selected centers, first, classified sampling was done based on organizational job positions (clinical and administrative), then, samples were selected with simple random selection method from each class with a specific Cochrane formula. Final sample size is 245 participants and data collection tool is a questionnaire. To assess TL, Bass \& Avolio questionnaire was used consisting of four dimensions (Intellectual stimulation, idealized influence, individualized consideration and inspirational motivation). This questionnaire has 36 questions and it is set based on five scale Likert (always, often, sometimes, rarely, never). Moreover, to assess the productivity Hersi \& Goldsmith questionnaire was used, consisting of seven dimensions (Job Recognition/knowledge, organizational support, motivation, performance feedback, reliability and environmental compatibility) this questionnaire includes 26 questions and is set based on a five scale Likert (Very much, much, to some extent, low and very low). To examine the questionnaire's validity, content validity, factor analysis and convergent validity were applied. Therefore, the questions were verified by experts, and a factor validity test was run on the questionnaire in the form of a confirmatory factor analysis to make sure of a relationship between each of the items with their associated variable. Noting the acquired results, factor loading of the research items is more than 0.5 which indicates a high validity for the questionnaire. Also, to examine the reliability of the questionnaire, Cronbach's alpha was used, which showed 0.9 for employee's productivity 
dimension and showed 0.88 for the transformational leadership dimension. This study was approved by the Ethics Committee of Iran University of Medical Sciences, Tehran, Iran. The research hypotheses were tested using descriptive statistics, e.g. frequency, percentage, mean and standard deviation and inferential statistics including multiple regression, Pearson correlation coefficient and analysis of variance to analyze the data and findings and components using structural equation modeling techniques and SPSS19 and Amos 24 with significance level of 0.05 percent. In order to demonstrate the significance of each of the model's parameters, T-test was applied, and impact factor was used to show the effect of transformational leadership on productivity.

\section{Results}

Based on descriptive statistics, $30 \%$ of the study population had an age less than 30 . Thirty-five percent of them were between 30 and 40 years old, and 23\% were between 40 and 50 years old. Only $12 \%$ were between 50 to 60 years old. Of the participants $65 \%$ were female and the rest were male (35\%). Regarding their occupations, 56\% work in financial affairs, $31 \%$ are nurses and $11 \%$ are physicians. In terms of job experience, $52 \%$ of the participants had less than 10 years occupational experience. Sixty-two percent of the population had a bachelor's degree, $12 \%$ had lower degrees and only $25 \%$ had a degree higher than a bachelor's degree. Concerning recruitment type, $49 \%$ were hired under national mandatory human resources services contracts for graduates of medical schools, $42 \%$ were on organizational contracts and only $8 \%$ had government/official permanent contracts. Moreover, based on the results from analysis of descriptive statistics of the research variables, average of TL and employees' productivity for the variables of each of these macro structures are presented in Tables 1,2. Results indicate that averages in all dimensions of research variables is less than three, which shows undesirable TL and employee productivity in Iran University of Medical Sciences.

In order to determine goodness of fit in the confirmatory factor analysis model, the below indicators shown in Table 3 were analyzed; goodness fitting indicators with chi-square indicator with freedom degree of 3.756, CFI indicator of 0.91 , IFI indicator of 0.82 and root mean square error of approximation (RMSEA) indicator of 0.153 . Findings show that the measuring model does not have a proper goodness of fitting, and requires amendments. To modify the measuring model, a number of criteria were applied so that the model and fitting indicators reach optimum/desirable level. The first criterion is omitting items with significance level higher that 0.05 or those with factor loading level less than 0.5 . The second criterion is correlation between errors for measuring the items since there was a significant correlation between some of the items, and it indicates similarity between the items. Findings from fitting indicators of the measuring model after modification are as below: chi-square two with freedom degree of 2.756, CFI indicator 0.95, IFI indicator 0.92, and RMSEA indicator 0.10 . These results show that the measuring model has a sound goodness of fit only after the modification. The research model was tested by structural modeling equations using Amos statistical software. P-value should be less than 0.05 for results with the significance of the correlation with 95\% confidence level (14). According to analysis for the assumptions of the model and the final model of the research, TL effect on employee productivity is confirmed with an impact factor of 0.83 and a significance level less than 0.05 shows the significance of the research assumption. It indicates that with one unit increase in TL, employees' productivity increases $83 \%$. The study validated the model in Figure 1 .

Table 1. Mean and standard deviation of transformational leadership

\begin{tabular}{|l|l|l|}
\hline Variables / statistical indicators & Average & Standard deviation \\
\hline Intellectual stimulation & 2.69 & 0.63 \\
\hline Idealized influence & 2.73 & 0.76 \\
\hline Inspirational Motivation & 2.73 & 0.83 \\
\hline Personal considerations & 2.45 & 0.87 \\
\hline
\end{tabular}

Table 2. Mean and standard deviation of employee productivity

\begin{tabular}{|l|l|l|}
\hline Variables / statistical indicators & Mean & SD \\
\hline Ability & 2.42 & 0.79 \\
\hline Clarity & 2.37 & 0.54 \\
\hline Help & 2.20 & 0.75 \\
\hline Assessment & 2.14 & 0.80 \\
\hline Validity & 2.47 & 0.66 \\
\hline Motivation & 2.04 & 0.89 \\
\hline Environment & 2.87 & 0.72 \\
\hline
\end{tabular}


Table 3. Reliability and validity results of the confirmatory factor analysis

\begin{tabular}{|c|c|c|c|c|c|}
\hline Variable & dimensions & $\begin{array}{l}\text { Cronbach's } \\
\text { alpha }\end{array}$ & $\begin{array}{l}\text { loading } \\
\text { factor }\end{array}$ & $\begin{array}{l}\text { significance } \\
\text { level }\end{array}$ & $\begin{array}{l}\text { Critical } \\
\text { ratio }\end{array}$ \\
\hline \multirow{7}{*}{ Employee productivity } & Ability & \multirow{7}{*}{0.9} & 0.84 & ---- & --- \\
\hline & Clarity & & 0.71 & $<0.001$ & 11.45 \\
\hline & Help & & 0.76 & $<0.001$ & 10.02 \\
\hline & Assessment & & 0.88 & $<0.001$ & 8.77 \\
\hline & Validity & & 0.87 & $<0.001$ & 9.86 \\
\hline & Motivation & & 0.84 & $<0.001$ & 8.54 \\
\hline & Environment & & 0.82 & $<0.001$ & 5.74 \\
\hline \multirow[t]{4}{*}{$\begin{array}{l}\text { Transformational } \\
\text { Leadership }\end{array}$} & $\begin{array}{l}\text { Intellectual } \\
\text { stimulation }\end{array}$ & \multirow[t]{4}{*}{0.88} & 0.83 & $\begin{array}{ll}---- \\
\end{array}$ & $\begin{array}{l}-- \\
-\end{array}$ \\
\hline & Idealized influence & & 0.72 & $<0.001$ & 10.92 \\
\hline & $\begin{array}{l}\text { Inspirational } \\
\text { Motivation }\end{array}$ & & 0.88 & $<0.001$ & 10.33 \\
\hline & $\begin{array}{l}\text { Personal } \\
\text { considerations }\end{array}$ & & 0.8 & $<0.001$ & 9.28 \\
\hline
\end{tabular}

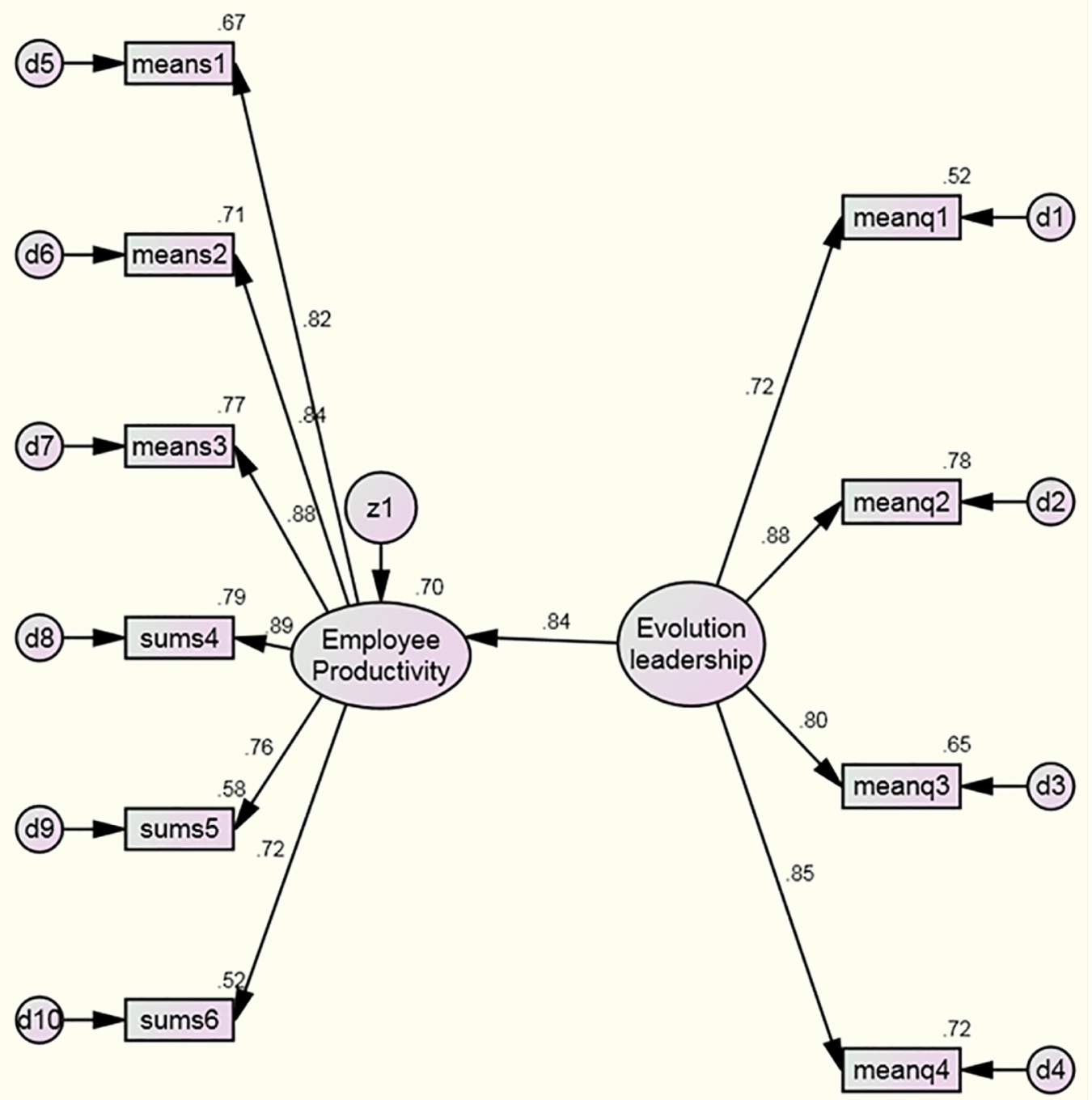

Figure 1. Final model of this research. Meanq1: intellectual stimulation, Meanq2: idealized influence, Meanq3: motivation, Meanq4: individual considerations, Means1: ability, Means2: clarity, Means3: help/assistance/aid, Means4: Evaluation, Means5: Credit, Means6: Motivation, Means7: Environment 


\section{Discussion}

This study aims to examine the effect of transformational leadership on employee productivity in teaching hospitals of Iran University of Medical Sciences. Findings and the structural model of the research indicate that TL is effective in employee productivity. Findings of this research are in line with those of Mehrabian et al.'s study in 2012 which showed that among affecting factors on human resources productivity, TL is the most influencing one to enhance productivity (15). In 2014, Mohammadi showed in his study that TL is also effective on human resources productivity (16). Another study in 2000 elaborated on the fact that TL type has a direct and positive relationship with employees' incentive, empowerment and productivity overall (17). Another research which was conducted in Singapore through 170 companies revealed that there is a substantial relationship between TL type and organizational performance on the whole, and improvement of human capital and effective management of human resources has a direct effect on it (18). Moreover, a study in 2013 exhibited that mangers' mode of leadership in an organization have a positive relationship with job satisfaction in individual and group scope which ultimately reflects in the performance of a person and teams (19). Another investigation in 2012 showed that TL has a major effect on job satisfaction and organizational commitment and both have effects on individual and organizational performance (20). On the other hand, results of this research showed that TL determines $83 \%$ of changes relating to workforce productivity. However, another study indicated less effect on workforce productivity by TL (19\%) and justifies it through the fact that leadership is not the only means to productivity optimization, rather, other affecting factors such as entrepreneurship, which is also an essential mediating variable, having an indirect influence (44\%) (21). Also, results of a review in 2011 showed that TL is superior in terms of anticipating employee performance rather than transactional leadership style (22). Based on the finding of the present study, and its comparison with others, it can be concluded that TL in an organization can be considered as a variable that has either direct or indirect effect on employees' productivity (through some mediating variables e.g. job satisfaction, team work and organizational culture). Therefore, it is indispensable to pay focused attention to transformational leadership and other mediating variables in an organization with the aim of cumulative individual productivity that overall enhancement of organizational performance seems inevitable. Noting the advantages and desirable outcomes of implementing transformational management methods, especially from the perspective of improving employee productivity and eventually organizational performance, it is recommended to authorities and decision makers to seek application and establishment of a transformation management system in hospitals. It seems essential to establish coherent working groups and appropriately plan change and transformation with regard to the nature and mission of hospitals.

\section{Limitations}

This study examined the level of transformational leadership on employee productivity among a sample of hospital personnel. In this study, personnel participation was voluntary and was conducted at one hospital in Tehran city, Iran. Therefore, the findings should be interpreted with caution since the participants were hospital personnel from a particular province of Iran and do not represent all hospital personnel in this country. More research in this area is needed before generalizing the study findings.

\section{Conclusions}

In the multifactorial theory of productivity and the systematic model for effective selection and recruitment of human resources in organizations, existence of effective leaders and managers who create transformation is the most prominent factor that can provide necessary facilities for increased human resources productivity. A critical challenge for transformational leaders in the third millennium is finding solutions to encourage each one of the employees to practice their potential capacities (23). On the other hand, based on the studies and literature review, TL is always pivotal with respect to its effects on the outcomes of organizations and their performances. If the leadership style of managers and decision makers has more tendency toward transformation style, more positive consequences will emerge among employees, and eventually the whole organization. Therefore, it is of considerable importance to commit attention to special training programs in organizations to develop and encourage behavior towards transformational leadership in order to increase employees' productivity.

\section{Acknowledgments:}

This study was supported by teaching hospital officials and staff. Thus, the authors find it incumbent to appreciate the president, managers and all the staff members of the mentioned hospital who offered their sincere contributions to this article. 


\section{Conflict of Interest:}

There is no conflict of interest to be declared.

\section{Authors' contributions:}

Samira Alirezaei and Soudabeh Vatankhah designed the study, Omid Khosravizadeh and Elmira Mirbahaeddin interpreted the data and wrote the paper. Mahtab Alikhani and Mobarakeh Alipanah gathered data, and conducted data analysis

\section{References:}

1) Ahmadi P. Design of productivity model with the manpower productivity management approach. Tehran: Tarbiat Modarres; 2000.

2) Farazja $M$, Khademi M. The relationship between transformational leadership style and interaction-oriented approach to organizational change. New ideas in Education. 2012; 6(4): 49-70.

3) Humphreys $\mathrm{JH}$, Einstein WO. Nothing new under the sun: transformational leadership from a historical perspective. Management Decision. 2003; 41(1): 85-95. doi: 10.1108/00251740310452934.

4) Mirkamali M, Shateri K. Clarifying the role of transformational leadership on organizational innovation trends. Journal of Innovation and Value Creation. 2014; 1(3): 21-31.

5) Amiti M, Wei SJ. Service offshoring, productivity, and Employment: Evidence from the United States: International Monetary Fund; 2005.

6) Alizade S, Tabibi J. Relationship between quality of work life and productivity of the management of social security hospitals of Tehran. Health Management. 2009; 11(34): 21-6.

7) Seyedin H, Ahadinejad B. Relationship between perceived organizational justice and efficiency in hospitals of Tehran University of Medical Sciences. The first student congress of clinical governance and continuous quality improvement. Tabtiz University of Medical Sciences. 2012.

8) Davis P, Milne B, Parker K, Hider P, Lay-Yee R, Cumming J, et al. Efficiency, effectiveness, equity (E3). Evaluating hospital performance in three dimensions. Health Policy. 2013; 112(1-2): 19-27. doi: 10.1016/j.healthpol.2013.02.008. PMID: 23537468.

9) Dimas G, Goula A, Soulis S. Productive performance and its components in Greek public hospitals. Oper Res Int J. 2012; 12(1): 15-27. doi: 10.1007/s12351-010-0082-2.

10) Blank JL, Eggink E. The impact of policy on hospital productivity: a time series analysis of Dutch hospitals. Health Care Manag Sci. 2014; 17(2): 139-49. doi: 10.1007/s10729-013-9257-8. PMID: 24258183.

11) Kim SY, Kim EK, Lim HM, Lee MY, Park KO, Lee KA. Structural Equation Modeling on Nursing Productivity of Nurses in Korea. J Korean Acad Nurs. 2013; 43(1): 20-9. doi: 10.4040/jkan.2013.43.1.20. PMID: 23563065.

12) Hayati $D$, Charkhabi M, Naami A. The relationship between transformational leadership and work engagement in governmental hospitals nurses: a survey study. Springerplus. 2014; 3: 25. doi: 10.1186/2193-1801-3-25. PMID: 24455469, PMCID: PMC3895439.

13) Top M, Akdere M, Tarcan M. Examining transformational leadership, job satisfaction, organizational commitment and organizational trust in Turkish hospitals: public servants versus private sector employees. The International Journal of Human Resource Management. 2015; 26(9): 1259-82. doi: 10.1080/09585192.2014.939987.

14) Wetzels M, Odekerken-Schröder G, Van Oppen C. Using PLS Path Modeling for Assessing Hierarchical Construct Models: Guidelines and Empirical Illustration. Mis Quarterly. 2009; 33(1): 177-95.

15) Mehrabian F, Nasiripour A, Keshavarz Mohamadian S. Investigating the significance of identified cases in manpower's productivity from staff and scientific mission's point of view in some colleges of Gilan university. Journal of Zanjan Medical Sciences University. 2011; 19(75): 94-106.

16) Barzoki AS, Mohamadi M. A survey of the impact of transformational leadership on manpower productivity with the mediating role of organizational entrepreneurship. Journal of Change Management. 2013; 6(12): 1-28.

17) Masi RJ, Cooke RA. Effects of transformational leadership on subordinate motivation, empowering norms, and organizational productivity. The International Journal of Organizational Analysis. 2000; 8(1): 16-47. doi: 10.1108/eb028909.

18) Zhu W, Chew IKH, Spangler WD. CEO Transformational Leadership and Organizational Outcomes: The Mediating Role of Human-Capital-Enhancing Human Resource Management. The Leadership Quarterly. 2005; 16(1): 39-52. doi: 10.1016/j.leaqua.2004.06.001. 
19) Braun S, Peus C, Weisweiler S, Frey D. Transformational Leadership, Job Satisfaction, and Team Performance: A Multilevel Mediation Model of Trust. The Leadership Quarterly. 2013; 24(1): 270-83. doi: 10.1016/j.leaqua.2012.11.006.

20) Atmojo M. The influence of transformational leadership on job satisfaction, organizational commitment, and employee performance. Business Studies. 2015; 5(2): 113-28.

21) Shaemi Barzaki A, Mohammadi M. The effect of transformational leadership on labor productivity with Mediating Role of Corporate Entrepreneurship. Journal of change management. 2016; 12(6): 1-28.

22) Wang G, Oh IS, Courtright SH, Colbert AE. Transformational leadership and performance across criteria and levels: A meta-analytic review of 25 years of research. Group \& Organization Management. 2011; 36(2): 223-70. doi: 10.1177/1059601111401017.

23) Rezaei L, Saatchi M. Connection between attitude toward effective human factors in productivity and wardens leadership style with organizational obligation on staff working in transmittal factories. Research in Psychological Department of Khorasgan University. 2008; 37(3): 129-46. 